\title{
Survival of Motoneurons in the Brachial Lateral Motor Column of Limbless Mutant Chick Embryos Depends on the Periphery
}

\author{
Mark E. Lanser, Jill L. Carrington, and John F. Fallon \\ Department of Anatomy, University of Wisconsin, Madison, Wisconsin 53706
}

\begin{abstract}
Motoneuron survival in the embryonic spinal cord is influenced by the presence or absence of the developing limb bud. We have recently begun a reexamination of the relationship between limb absence and motoneuron survival in a nonsurgical limb deletion model, the limbless mutant chick embryo. As in surgically limbdeleted normal embryos, only $10 \%$ of the motoneurons that are intially produced in the limbless mutant lateral motor column (LMC) survive the embryonic period (Lanser and Fallon, 1984). We now report that, when supplied with a normal periphery (i.e., a normal limb bud), more than $40 \%$ of the motoneurons initially produced in the limbless LMC survive the embryonic period. Motoneuron cell counts in one-winged limbless embryos reveal that over 3.5 times as many motoneurons survive the cell death period in the LMC on the side with the limb than on the opposite, limbless side. This demonstrates the dependence of embryonic LMC motoneurons on the developing limb for survival and indicates that the limbless mutant is an appropriate model for studying the death and survival of LMC motoneurons during development. Using the limbless mutant to study LMC motoneuron survival eliminates the complication of possible direct surgical effects on motoneuron death. In addition, we found that a substantial effect of the wing on rescuing $\mathrm{LMC}$ motoneurons was exerted prior to the 6th day of embryonic development. Normally, little cell loss occurs in the brachial LMC during this time. Accordingly, motoneuron death in the limb-deprived brachial LMC, whether in surgically limb-deleted normal embryos or in genetically limbless embryos, is accelerated with respect to cell death in the normal brachial LMC.
\end{abstract}

Since cell death was first established as an integral part of the development of specific nerve centers (Hamburger and LeviMontalcini, 1949), the phenomenon of naturally occurring neuronal death has been widely documented but incompletely understood (for a historical review, see Oppenheim, 1981). One neuronal population where cell death has been extensively studied is the lateral motor column (LMC) of the spinal cord (see Lamb, 1984, for review). The LMC contains the motoneurons that innervate the muscles of the vertebrate limb. It has been

Received Nov. 15, 1985; revised Feb. 21, 1986; accepted Mar. 20, 1986

This work was supported by NIH T32HD07118 and T32AM07389, NSF PCM8406338, and funds provided by the University of Wisconsin Graduate School. A preliminary report of this work was presented at the 97 th annual session of the American Association of Anatomists Meeting in Seattle. We thank Eugenie Boutin, Allen W. Clark, Leah Dvorak, Rebecca Fuldner, Lewis B. Haberly, John K. Harting, Steven Kornguth, Karen Krabbenhoft, Mary P. Savage, David B. Slautterback, and William Todt for their helpful criticism in preparing the manuscript. We also thank Asit K. Banerjee, Director, University of Wisconsin Statistics Laboratory, for his aid in the analysis of data, Bob Schlotthauer for preparing the graph, William Todt for help with the computer, and B. Kay Simandl for technical assistance in all aspects of this work.

Correspondence should be addressed to Dr. John F. Fallon, University of Wisconsin, Department of Anatomy, 1300 University Avenue, Madison, WI 53706.

Copyright (C) 1986 Society for Neuroscience 0270-6474/86/092551-07\$02.00/0 repeatedly demonstrated that the number of motoneurons in the $\mathrm{LMC}$ is related in some way to the size of the peripheral field, i.e., the developing limb bud (Hamburger, 1934; Shorey, 1909; for review, see Oppenheim, 1981). The periphery is thought to determine LMC motoneuron number by regulating the amount of motoneuron death that occurs. The reduction in motoneuron number observed following limb bud extirpation is thought to represent an increase in the normal amount of motoneuron death (Hamburger, 1958, 1975; Laing, 1982a, b; Lamb, 1981; Oppenheim et al., 1978; Prestige, 1967). Conversely, the increase in motoneuron number seen following limb bud addition is thought to be caused by a decrease in the amount of death that normally occurs (Hamburger, 1975; Hollyday and Hamburger, 1976; Hollyday and Mendel, 1976; Lamb, 1979; Maheras and Pollack, 1985).

Although the increased motoneuron death following surgical limb bud removal may represent a simple numerical enhancement of the normally occurring phenomenon, evidence in support of this assumption is only circumstantial (Chu-Wang and Oppenheim, 1978a, b; Oppenheim et al., 1978; for review, see Hamburger and Oppenheim, 1982). The induced loss of motoneurons following peripheral deletion may differ in qualitative as well as quantitative ways from naturally occurring motoneuron death (Lamb, 1984; Lanser and Fallon, 1984).

Surgical manipulation of the developing chick limb bud seems to have no effect on the production, migration, or initial differentiation of motoneurons in the developing spinal cord (ChuWang and Oppenheim, 1978a, b; Hamburger, 1958; Hollyday and Hamburger, 1976; Oppenheim et al., 1978). Nerve trajectories are unaltered after surgical displacement of the developing limb bud (Stirling and Summerbell, 1977), and appropriate connections with the target musculature are established (Hollyday, 1981; Hollyday et al., 1977; Whitelaw and Hollyday, 1983). However, surgical intervention might have undetected effects on the developing motoneurons that predispose them to a degenerative fate. The acceleration of motoneuron death after surgical removal of the periphery (Laing, 1982a; Oppenheim et al., 1978) might reflect a basic difference in the cell death process itself. One possibly significant observation in limb bud-extirpated embryos is that the outgrowing spinal nerves end abnormally in a "neuroma" that is far removed from the normal limb attachment site (Hamburger, 1958; Oppenheim et al., 1978; but see Tosney and Landmesser, 1984). This may contribute to, or be indicative of, changes in the neurons themselves.

Recently, in order to circumvent possible direct surgical effects on motoneuron survival, we have begun an analysis of LMC development in the limbless mutant chick embryo (Fallon et al., 1983; Lanser and Fallon, 1984). The limbless mutation results in the failure of limb development at all 4 sites (Fallon et al., 1983; Prahlad et al., 1979). The phenotypic expression of the limbless gene appears to be mediated through an effect on the ectodermal cell layer. Embryos homozygous for the limbless gene do not form an apical ectodermal ridge (Fallon et al., 
Table 1. Peripheral and host relationships for experimental and control groups

\begin{tabular}{|c|c|c|c|c|}
\hline Host & Normal host & & Limbless host & \\
\hline$\overline{\text { Side }}$ & Left & Right & Right & Left \\
\hline Periphery & Unoperated (normal wing) & Operated (normal wing) & Operated (normal wing) & Unoperated (no wing) \\
\hline Group & Normal control & Experimental control & Experimental & Limbless control \\
\hline
\end{tabular}

1983). Subsequently, the limb bud fails to grow beyond stage 20, and the underlying mesodermal cells die (Fallon et al., 1983). In addition to the absence of limbs in limbless embryos, abnormalities have been noted in the limb girdles (J. F. Fallon, B. K. Simandl, and J. L. Carrington, unpublished observations). It is also well documented that there is an increased loss of motoneurons from both the brachial and lumbar LMCs of $1 \mathrm{imb}$ less embryos (Fallon et al., 1983; Lanser and Fallon, 1984; and present report). We previously speculated that this additional cell loss was due to the absence of limbs in these embryos. However, the possibility remained that the increased motoneuron death was caused by a pleiotropic effect of the mutant gene on the neuroectodermally derived motoneurons. The present experiments were designed to test the response of the mutant LMC to a normal limb in the periphery. By replacing the affected ectoderm in the region of the future wing bud before expression of the limbless gene was apparent, we were able to distinguish the effects of the gene on limb development from the possible cffects on motoneuron survival.

\section{Materials and Methods}

Normal White Leghorn embryos were obtained from Sunnyside Poultry Farm, Inc., Oregon, WI. Limbless mutant embryos were obtained from a flock of heternzygous limbless carriers maintained at the University of Wisconsin-Madison. All eggs were incubated in a forced-draft incubator at $37-38^{\circ} \mathrm{C}$. Eggs were removed at $2.5 \mathrm{~d}$ of incubation, windowed according to standard techniques, then resealed and reincubated until the desired stage for operation was attained. All embryos were staged according to the series of Hamburger and Hamilton (1951).

\section{Epithelial grafts}

We utilized a pre-limb bud stage recombinant procedure to permit normal wing development as early as possible in limbless embryos (described in detail in Carrington and Fallon, 1984). With this method, the ectoderm from the prospective right wing region of developing embryos was removed at stage 15 . Stage 15 is before limb buds form and before brachial LMC motoneurons are born in chick embryos (Hollyday and Hamburger, 1977). The host ectoderm opposite somites 14 to 21 was first lightly stained with Nile Blue A, then removed with glass needles and a forceps. A block of flank mesoderm and ectoderm was removed from a normal donor embryo and treated with EDTA to separate the 2 tissues. The donor ectoderm was then grafted to the denuded host presumptive right wing mesoderm. In both normal and limbless host embryos, normal recombinant right wings formed in the majority of cases (Carrington and Fallon, 1983; Fallon et al., 1983; J. L. Carrington and J. F. Fallon, unpublished observations).

A series of grafts was made to embryos from limbless heterozygote matings. After grafting, the embryos were reincubated and allowed to develop until 6,12 , or $18 \mathrm{~d}$, when they were taken from the egg and prepared for motoneuron counting as described below. The wings from the graft site were removed and examined separately for completeness by staining with Victoria bluc to revcal thcir cartilage structurc in wholemount preparation. Since our purpose was to test the effect of a normal periphery on development of the limbless LMC, only those wings that appeared normal both on gross inspection and on examination of their cartilage structure were included in the present study. An exception was made for a single $12 \mathrm{~d}$ limbless embryo that had a slight separation of the distal phalanges of digits 3 and 4 . Cell counts for this embryo indicated no effect on motoneuron survival, and it was included in the data analysis along with the other experimental embryos.

\section{Controls}

Three sets of control data were obtained for this experiment.

1. Limbless control. Since ectoderm grafts resulted in the development of normal right wings in limbless hosts, the unoperated left sides of these same embryos provided data on the development of the brachial LMC under limbless peripheral conditions.

2. Normal control. Since the ectoderm grafts were done at stage 15 , when normal and limbless embryos were indistinguishable, three-fourths of the experiments were done on phenotypically normal hosts. The unoperated left sides of the normal hosts provided data on the development of the normal LMC.

3. Experimental control. The operated right sides of these same normal hosts allowed us to assess the effect of the ectoderm grafting procedure on motoneuron survival. Comparing the right (operated) LMCs of normal and limbless hosts allowed us to determine the effects of the limbless genotype on LMC development. To further clarify the relationships between the experimental and control groups, they are listed in Table 1 by the type of host and the peripheral conditions.

\section{Wing bud grafts}

Because of the technical difficulty of the ectoderm grafting procedure, and to permit identification of the host phenotype at the time of operation, a second method was devised to permit wing development in limbless embryos. With this method, the regressing right wing bud of a limbless host was removed surgically at stage 19 or 20 . At this stage, the limbless mutation first becomes evident as a dip in the normally smooth contour of the wing bud tip (Fallon et al., 1983). Right wing buds were also removed from comparably staged normal donor embryos by dissecting them free with a glass needle just lateral to the edge of the somites. The normal donor wing bud was then grafted, in normal position and orientation, to the vacant host site in a limbless embryo by pinning it in place with a piece of fine platinum wire (diameter, 0.025 $\mathrm{mm}$ ). This resulted in the development of normal right wings in limbless embryos. The left (unoperated) LMC again served as the limbless control. These embryos were reincubated and allowed to develop until 12 or $18 \mathrm{~d}$, when they were removed and processed in the same manner as the embryos that received ectoderm grafts. In a few preliminary experiments, quail wing buds were used as grafts to both normal and limbless hosts. The unique heterochromatin marker visible in the quail cell nuclei after reacting with the Feulgen reagent (LeDouarin and Barq, 1969) allowed us to determine which tissues were derived from the grafted wing bud. These embryos were allowed to develop until $10 \mathrm{~d}$; they were then fixed and stained en bloc with the Feulgen reagent according to the method of Carrington and Fallon (1984). After staining, these embryos were prepared for viewing in the light microscope as described below.

\section{Tissue preparation}

The method of tissue preparation was as described previously (Lanser and Fallon, 1984) and is summarized here. All tissues were fixed (first for a few hours on ice, then overnight at $4^{\circ} \mathrm{C}$ ) in a solution of $95 \%$ alcohol, $40 \%$ formaldchydc and glacial acctic acid in a ratio of 17:2:1. Six- and 12-d embryos were eviscerated and then fixed as above. Afterward, the tissues were stained en bloc with hematoxylin according to the method of Wenger (1951). In $18 \mathrm{~d}$ embryos, the brachial spine was dissected free prior to fixation, and decalcified prior to staining. The tissues were embedded in paraffin and serially sectioned in a plane transverse to the long axis of the spinal cord. The sections were mounted on albumen-coated slides for viewing in the light microscope. Six-day embryos were sectioned at $8 \mu \mathrm{m} ; 10-, 12-$, and $18-\mathrm{d}$ embryos at $12 \mu \mathrm{m}$. 


\section{Motoneuron counts}

Living and dead motoneurons were counted in the brachial LMC according to the method of Hamburger (1975). LMC motoneurons were identified not only by their location, but also by their histological appearance. Living motoneurons were characterized by their large size, dark stain, and the presence of at least one dense nucleolus within the lightly stained nucleus. Degenerating motoneurons were counted only if distinctly pycnotic. Every 8 th section was counted at $\times 1250$ in $6 \mathrm{~d}$ embryos. Every 10th section was counted at $\times 400$ in $12 \mathrm{~d}$ embryos and at $\times 250$ in $18 \mathrm{~d}$ embryos. All counts were done directly in the light microscope with the aid of a 400 -square ocular grid. The total number of motoneurons in the brachial LMC was determined by calculating the average number of motoneurons per section counted and multiplying by the total number of sections in the brachial LMC. The calculation was done separately for living and dead motoneurons in each LMC. No correction was made for the double counting of nuclei because the section thickness was always much larger than the nucleolar diameter (Konigsmark, 1970; see also Lanser and Fallon, 1984). A degeneration index was also calculated for each LMC. This was obtained by dividing the number of dead motoneurons by the total number of motoneurons (living plus dead) in the LMC (see Hamburger, 1975).

\section{Data analysis}

The brachial LMC motoneuron population normally peaks on the 6th day of embryonic development (approximately stage 28) and is subsequently depleted by a prolonged phase of cell death (Laing, 1982a; Lanser and Fallon, 1984; Oppenheim and Majors-Willard, 1978). Therefore, motoneuron counts at $6 \mathrm{~d}$ should yield the maximum initial brachial LMC population. Since there is little or no overlap between the periods of LMC assembly and LMC depletion (Hamburger, 1975; Hollyday and Hamburger, 1977), cell counts at later stages should accurately reflect the number of cells lost from the LMC, presumably due to cell death. The rate at which dead cells are removed from the LMC is not known. However, the sampling interval in the present study 6 d) virtually eliminates the possibility that the same dead cell could be counted twice. Therefore, counts of dead motoneurons at any stage provide an estimate of the rate of cell death occurring in the LMC at the time of fixation. In addition, the degeneration index provides an estimate of the rate of cell loss occurring in the LMC as a percentage of the total number of cells present at a given time.

The rostrocaudal distribution of motoneurons within the brachial LMC was determined by the method of Oppenheim and Majors-Willard (1978). This was done by dividing the LMC into 10 equal segments, referred to as "bins" (Laing, 1982b), along the rostrocaudal length of the column. The number of motoneurons in each bin was determined by multiplying the average number of motoneurons per section counted within the bin by the total number of sections spanned by the bin.

Statistical comparisons of cell counts (living or dead) from the right and left sides of the same host embryos, e.g., the right (operated) and left (unoperated) sides of limbless hosts, were done using the Wilcoxon signed rank test for paired samples. For comparisons of cell counts obtained from different host embryos, e.g., the right (operated) side of normal hosts and the right (operated) side of limbless hosts, the MannWhitney $U$ test for independent random samples was used. Comparisons of the degeneration indexes from different host embryos were done using Student's $t$ test for independent random samples. Comparisons of the degeneration indexes from both sides of the same hosts were done using Student's $t$ test for paired differences.

\section{Results}

\section{General}

The ectoderm grafting procedure resulted in the development of well-formed wings on the right side of limbless host embryos. There was no visible effect on the left, unoperated side. The experimentally produced wings on limbless embryos appeared to move normally and looked normal in every respect. Examination of the histological sections revealed a striking asymmetry. All structures on the right side of limbless embryos that were provided with a normal ectoderm, including the proximal wing musculature, appeared normal in size and composition.

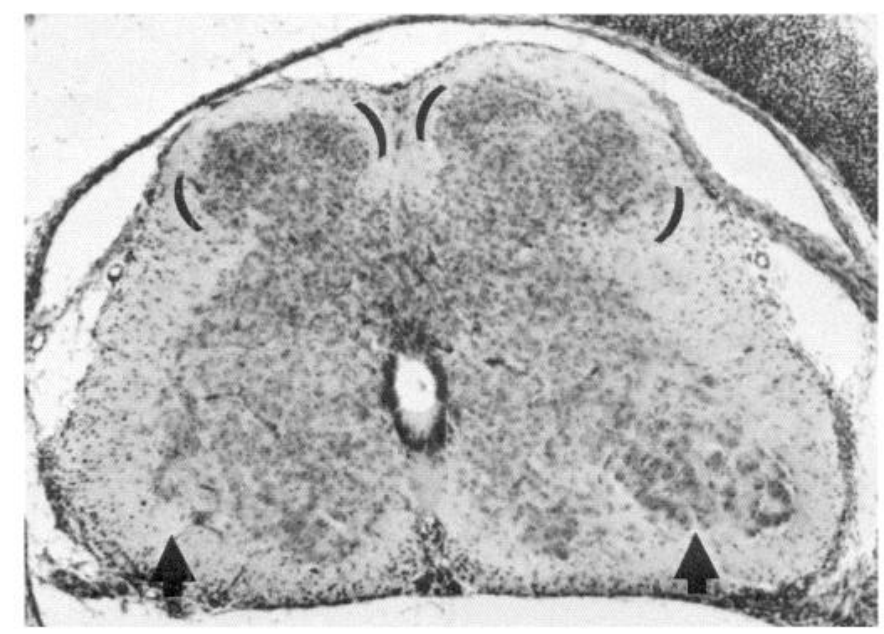

Figure 1. Cross section through the brachial spinal cord of a $12 \mathrm{~d}$ experimental limbless embryo. The section is at the level of segment 15 in a limbless host that had a normal ectoderm grafted to the right wing region at stage 15. The LMCs are indicated by the arrows. More motoneurons are present on the side where the wing is present (right) than on the opposite limbless side (left). In addition, the absence of a wing is reflected in the size of the dorsal horn of the spinal cord (brackets), which is smaller on the left than on the right side. $\times 82$.

The left, limbless side was dramatically hypoplastic. The asymmetry extended to the vertebrae and spinal cord, where normalappearing dorsal root ganglia, dorsal horns, and lateral motor columns were present on the right and corresponding hypoplastic structures on the left (Fig. 1).

The same general results were obtained with wing bud grafts. Examination of $10 \mathrm{~d}$ normal and limbless hosts with grafted quail wings revealed that only structures associated with the wing contained graft tissue. These included all of the wing skeletal elements, part of the shoulder girdle, and all of the wing musculature, including the entire pectoralis and the intrinsic shoulder muscles (Sullivan, 1962). Interestingly, the $10 \mathrm{~d}$ grafted quail wings were seen to contain some cells of chick origin. These were always located in close association with nerve bundles and were presumably Schwann cells, which are known to be of neural crest origin (LeDouarin, 1980).

\section{Motoneuron survival}

Cell counts of the total number of living and dead motoneurons in the brachial LMC are listed in Tables 2 and 3, respectively.

\section{Normal hosts}

At each of the times investigated, there was no statistically significant differences between the total number of living motoneurons in the LMCs on the ectoderm-grafted right side (experimental control) and the unoperated left side (normal control) of normal hosts (day 6: $p=0.250$, day 12: $p=0.624$, day 18: $p=0.876$ ). Combining the data for both sides, $57 \%$ of the motoneurons initially present in the normal brachial LMC died between 6 and $18 \mathrm{~d}$ of embryonic development. Fifty-three percent of these were lost between days 6 and 12 and another $4 \%$ between days 12 and 18 . In other words, about 9275 motoneurons died between 6 and $12 \mathrm{~d}$ and roughly another 725 between 12 and $18 \mathrm{~d}$. Both sides of normal hosts exhibited a low level of cell death at both 6 and 12 d (Table 3). No statistically significant differences were noted between the 2 sides for either the number of dead cells or the degeneration index [day $6: p=0.718$ (cells), $p>0.5$ (degeneration index); day 12: $p=$ 0.438 (cells), $p>0.2$ (degeneration index)]. 


\begin{tabular}{|c|c|c|c|c|c|}
\hline \multirow{2}{*}{$\begin{array}{l}\text { Days } \\
\text { incuba- } \\
\text { tion }\end{array}$} & \multirow[b]{2}{*}{$\begin{array}{l}\text { Type of } \\
\text { operation }^{a}\end{array}$} & \multicolumn{2}{|l|}{ Normal hosts } & \multicolumn{2}{|l|}{ Limbless hosts } \\
\hline & & $\begin{array}{l}\text { Normal } \\
\text { control }\end{array}$ & $\begin{array}{l}\text { Experimental } \\
\text { control }\end{array}$ & Experimental & $\begin{array}{l}\text { Limbless } \\
\text { control }\end{array}$ \\
\hline 6 & Epi & $\begin{array}{l}17,362 \pm 821 \\
(n=5)\end{array}$ & $\begin{array}{l}17,728 \pm 1098 \\
(n=5)\end{array}$ & $\begin{array}{l}15,646 \pm 1400 \\
(n=6)\end{array}$ & $\begin{array}{l}12,604 \pm 1244 \\
(n=6)\end{array}$ \\
\hline \multirow[t]{2}{*}{12} & Epi & $\begin{array}{l}8205 \pm 965 \\
(n=10)\end{array}$ & $\begin{array}{l}8239 \pm 1065 \\
(n=10)\end{array}$ & $\begin{array}{l}7244 \pm 1108 \\
(n=7)\end{array}$ & $\begin{array}{l}1930 \pm 473 \\
(n=7)\end{array}$ \\
\hline & Bud & & & $\begin{array}{r}6352 \pm 688 \\
(n=8)\end{array}$ & $\begin{array}{r}1833 \pm 339 \\
(n=8)\end{array}$ \\
\hline $18^{b}$ & Epi + bud & $\begin{array}{l}7478 \pm 1092 \\
(n=4)\end{array}$ & $\begin{array}{l}7564 \pm 713 \\
(n=4)\end{array}$ & $\begin{array}{l}6618 \pm 1268 \\
(n=3)\end{array}$ & $\begin{array}{l}1849 \pm 1045 \\
(n=3)\end{array}$ \\
\hline
\end{tabular}

\footnotetext{
The mean number of motoneurons, $\pm \mathrm{SD}$, and the number of LMCs counted $(n)$ are given for each group.

${ }^{a}$ Epi, epithelial grafts; Bud, wing bud grafts.

${ }^{n}$ All of the $18 \mathrm{~d}$ normal hosts received epithelial grafts; 2 of the 3 limbless hosts received wing bud grafts.
}

\section{Limbless hosts: Ectoderm grafts}

Limbless control (left) LMC. Development of the brachial LMC on the unoperated left side of limbless hosts was comparable to our previously published results on brachial LMC development in limbless embryos (Lanser and Fallon, 1984). Eighty-five percent of the initial population of motoneurons in the limbless control brachial LMC was lost between days 6 and 12. Little additional cell loss occurred through day 18 . In other words, approximately 10,670 cells were lost between days 6 and 12 and about 80 cells between days 12 and 18 . Both the degeneration index and absolute counts of dead motoneurons indicated that there was a high rate of cell loss occurring in the limbless LMC on day 6 and a relatively low rate on day 12 (Table 3 ).

Experimental (right) LMC. Development of the LMC on the ectoderm-grafted right side of one-winged limbless hosts was similar to normal LMC development. Fifty-eight percent of the initial motoneuron population died between day 6 and day 18 . There was a $54 \%$ loss of motoneurons between 6 and 12 days and another $4 \%$ between 12 and 18 days. Approximately 8350 motoneurons were lost between 6 and 12 days and roughly another 630 cells between days 12 and 18. As in the normal embryos, there was a relatively low level of cell death on both day 6 and day 12 (Table 3).

Experimental vs limbless control (right vs left) LMCs. Comparing the LMCs on the ectoderm-grafted right and unoperated left sides in one-winged, ectoderm-grafted limbless hosts allowed us to determine the effect of a normal periphery on mo- toneuron survival in the limbless LMC. First, there were more motoneurons present in the right than in the left LMCs at each stage investigated (Table 2; day 6: $p=0.016$, day 12: $p=0.008$, day 18: $p=0.125$ ). Second, the presence of normal wings on the right side diminished the percentage of the initial population lost from the LMC during the embryonic cell death period ( 58 vs $85 \%$ ). Third, the presence of wings reduced the absolute number of cells lost from the limbless LMC between 6 and 12 $\mathrm{d}$ from 10,670 to $8350-$ a reduction of 2320 motoneuron deaths. Conversely, 550 more cells died in the limbless LMC between 12 and $18 \mathrm{~d}$ when a wing was present ( 630 vs 80 ).

Considering this third point; if the presence of a wing prevented 2320 motoneurons from dying in the limbless LMC between 6 and $12 \mathrm{~d}$, the only way to account for the presence of 5300 more motoneurons in the right than the left limbless LMC on day 12 is to presume the wing had an effect before the 6th day. Indeed, on day 6 there were almost 3000 more motoneurons in the right LMC than in the left. In addition, on day 6 both the total number of dead motoneurons and the degeneration index were significantly decreased in the limbless LMC when a wing was present (cells: $p=0.016$; degeneration index: $p<0.001$ ). This suggests that the additional motoneurons in the experimental LMC were prevented from dying by the developing wing bud before the 6 th day. On day 12 there actually appeared to be more dead cells on the right than on the left $(p=$ $0.016)$, but this was not reflected in the degeneration index $(p$ $>0.05)$.

Table 3. Mean number of dead motoneurons in the brachial LMC

\begin{tabular}{|c|c|c|c|c|c|}
\hline \multirow{2}{*}{$\begin{array}{l}\text { Days } \\
\text { incuba- } \\
\text { tion } \\
\end{array}$} & \multirow{2}{*}{$\begin{array}{l}\text { Type of } \\
\text { operation }\end{array}$} & \multicolumn{2}{|l|}{ Normal hosts } & \multicolumn{2}{|l|}{ Limbless hosts } \\
\hline & & Normal control & Experimental control & Experimental & Limbless control \\
\hline 6 & Epi & $\begin{array}{l}87.8(0.50) \pm 64.4(0.38) \\
(n=5)\end{array}$ & $\begin{array}{l}81.8(0.46) \pm 46.8(0.26) \\
(n=5)\end{array}$ & $\begin{array}{l}117.2(0.74) \pm 20.7(0.10) \\
(n=6)\end{array}$ & $\begin{array}{l}355.0(2.75) \pm 81.9(0.65) \\
(n=6)\end{array}$ \\
\hline 12 & Epi & $\begin{array}{l}22.4(0.28) \pm 19.9(0.24) \\
(n=10)\end{array}$ & $\begin{array}{l}36.0(0.50) \pm 46.2(0.69) \\
(n=10)\end{array}$ & $\begin{array}{l}37.6(0.49) \pm 37.4(0.46) \\
(n=7)\end{array}$ & $\begin{array}{l}4.1(0.21) \pm 7.5(0.37) \\
(n=7)\end{array}$ \\
\hline & Bud & & & $\begin{array}{l}17.0(0.26) \pm 21.1(0.32) \\
(n=8)\end{array}$ & $\begin{array}{l}\quad 4.9(0.27) \pm 7.3(0.38) \\
(n=8)\end{array}$ \\
\hline
\end{tabular}

The mean number of dead motoneurons, \pm SD, and the number of LMCs counted $(n)$ are given for each group. The numbers in parentheses are the degeneration index, and its standard deviation, for each group. No degenerating motoneurons were observed in any of the $18 \mathrm{~d}$ embryos.

${ }^{a}$ Epi, epithelial grafts; Bud, wing bud grafts. 
Limbless hosts vs normal hosts. By comparing the LMCs on the ectoderm-grafted right sides of limbless and normal hosts (experimental and experimental control), any direct effect of the limbless gene on motoncuron number could be detected. There were about 2000 fewer motoneurons in the right limbless LMC than in the right normal LMC on day 6, and about 1000 fewer on day 12 (Table 2). As a percentage of normal, the right limbless LMC contained about $89 \%$ as many cells on both day 6 and day 12 . Neither of these differences was statistically significant (day 6: $p=0.126$; day 12: $p=0.088$ ). However, when the data from both 6 and 12 days were pooled for each of the 2 groups (and scaled appropriately to account for the loss of cells between 6 and 12 days), it was apparent that there were fewer motoneurons in the right limbless LMC (where a normal wing was present) than in the right normal LMC $(p=0.0106)$. This slight hypoplasia most likely represents a pleiotropic effect of the limbless gene. The number of dead motoneurons in the right LMCs of limbless and normal hosts was similar on both 6 and $12 \mathrm{~d}$ $(p=0.3788$ and $p=0.8126$, respectively). However, because of the presence of fewer living cells, there was a slight increase in the degeneration index of the right limbless LMC compared to the right normal on day $6(0.74$ vs $0.46,0.02<p<0.05)$. This was no longer apparent on day $12(0.49$ vs $0.50, p>0.8)$.

\section{Limbless hosts: Wing bud grafts}

Grafting a normal wing bud to the right side of a limbless embryo at stage 20 had an effect on motoneuron survival similar to that seen after grafting a normal ectoderm at stage 15 . Over 3.5 times as many motoneurons were present on day 12 in the LMC on the wing bud-grafted right side than on the unoperated left side $(p=0.004)$. Comparing the (operated) right LMCs in wing budand ectoderm-grafted limbless hosts revealed that the 2 operations rescued about the same number of motoneurons in the limbless LMC through day $12(p=0.156)$. However, examination of the rostrocaudal distribution of motoneurons in the 2 LMCs revealed that there may have been subtle differences not indicated by the total motoneuron counts (Fig. 2). It is apparent that following wing bud grafting there was a shift in the motoneuron population toward more caudal levels of the LMC. This altered distribution may have been due to the fact that despite our efforts to pin the graft in a normal position it might have healed slightly posterior to the host wing site. This could have been due to extrinsic factors beyond our control, such as the adjacent beating heart.

\section{Discussion}

In this report we have demonstrated that the presence of a normal wing prevents the increased loss of brachial motoneurons that normally occurs in the limbless LMC. This indicates that the increased loss of motoneurons from the limbless LMC is not due to an effect of the gene on motoneuron survival but is secondary to the absence of limbs. We previously found that, in the absence of limbs, the limbless LMC developed like the limb-deleted normal LMC, i.e., motoneuron death was increased and accelerated compared to normal (Lanser and Fallon, 1984). In this report we have also demonstrated that the acceleration of motoneuron death in the limbless LMC is prevented by the developing limb bud. Through this series of studies we have eliminated the possibility that surgery or the formation of a neuroma after surgical limb removal (see Hamburger, 1934; Oppenheim et al., 1978) directly influences motoneuron death. Accordingly, because of the similarities in the development of genetically normal and genetically limbless LMCs, we conclude that the additional cell loss that occurs after target deletion is not a direct result of the mode of peripheral elimination (i.e., surgery or cell death), but is caused by the absence of the limb. These studies confirm the dependence of

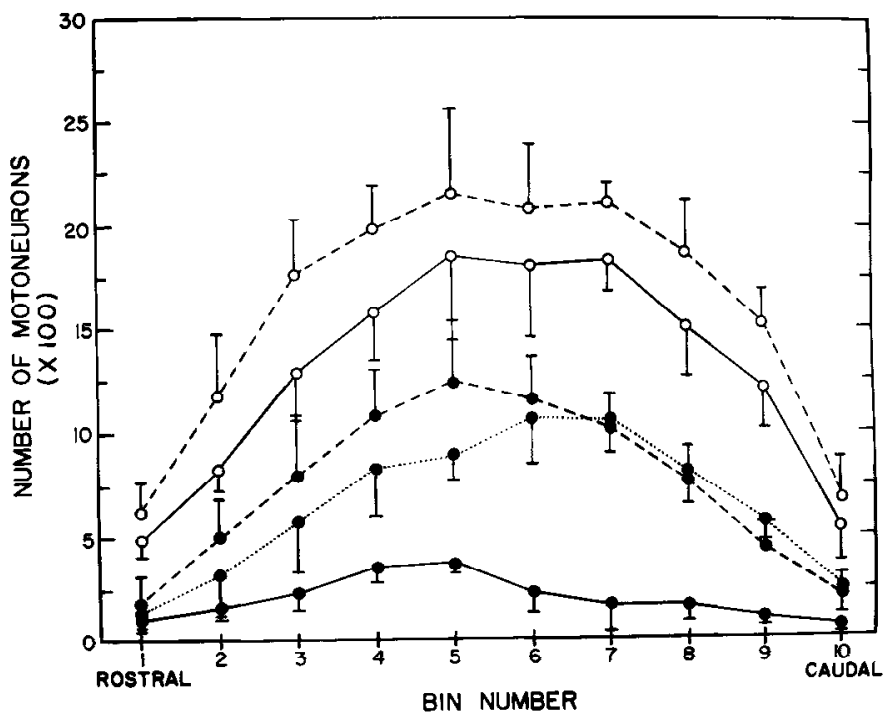

Figure 2. Rostrocaudal distribution of living motoneurons in the right and left LMCs of one-winged limbless embryos. The mean number of motoneurons for each bin in the brachial LMC was plotted from rostral (I) on the left to caudal (10) on the right. The vertical bars indicate the SEM. The open dots indicate data for day 6 ; the solid dots indicate data for day 12. The solid lines illustrate the limbless left LMC data (the unoperated side of a limbless host); the dashed lines illustrate the limbless right LMC data (the operated side of a limbless host) after ectoderm grafting; and the dotted line indicates the limbless right LMC data after wing bud grafting. The effect of a normal wing on the survival of motoneurons in the limbless brachial LMC is already apparent throughout the rostrocaudal extent of the column on day 6 . On day 12 , after much cell loss has occurred, the survival-enhancing effect of the wing is apparent after both ectoderm grafting (dashed line, solid dots) and wing bud grafting (dotted line, solid dots). Comparison of the results of wing bud and ectoderm grafting procedures at day 12 indicates that, despite similar effects on the total survival of motoneurons, there is an apparent decreased survival in the rostral bins after wing bud grafting.

LMC motoneurons on the limb bud for survival during embryonic development.

Another experimental embryogenetic system that has been exploited in much the same way as the limbless chick embryo is the eyeless axolotl (first described by Humphrey, 1969; for review, see Harris, 1983). Harris (1982) has shown that several irregularities of the central visual centers, and the abnormal dark body pigmentation seen in the mutants, are corrected by the transplantation of normal eyes to eyeless salamanders. He concluded that these defects were not the result of a pleiotropic gene effect but were due to the lack of some information normally provided by the developing eye. Similarly, we have shown that the increased cell loss in the limbless LMC is corrected by a normal limb. We conclude that the death of limbless motoneurons is not due to a gene effect but results from the absence of some information normally provided by the developing limb bud. We believe that the limbless mutant can be utilized in much the same way as the eycless axolotl to further our understanding of neural development. The normal development of the limbless LMC in both the presence and absence of the developing limb bud makes it an appropriate model for studying embryonic neuronal death. Limbless embryos may be useful for future work on LMC motoneuron death because they possess a consistent degree of limb elimination without the complicating variability and mortality necessarily accompanying surgical limb removal.

In this study we observed that the effect of a wing bud on rescuing motoneurons in the limbless LMC was apparent as an increased cell number on day 6 . In addition, the presence of a wing decreased the number of dead motoneurons present in the 
limbless LMC on day 6 . We therefore conclude that the developing wing bud influences motoneuron survival in the limbless LMC by preventing the death of motoneurons before the 6 th day of embryonic development. These data further illustrate the previously documented acceleration of motoneuron death in the target-deprived brachial LMC (Laing, 1982a; Lanser and Fallon, 1984). The bulk of cell loss in the limbless brachial LMC occurs between 4.5 and $8 \mathrm{~d}$ of development (Lanser and Fallon, 1984). Normally, the bulk of cell death in the brachial LMC occurs after $8 \mathrm{~d}$ (Laing, 1982a; Lanser and Fallon, 1984; Oppenheim and Majors-Willard, 1978). Only about $10 \%$ of the initial population of motoneurons is lost before this time (Lanser and Fallon, 1984). These observations, along with the present results, indicate that in the absence of the developing limb bud, most of the cells that die in the LMC do so before the bulk of cell death normally would have occurred. Therefore, the limb bud promotes motoneuron survival before the time when most LMC motoneurons normally begin to die.

A question that arises is whether the acceleration of motoneuron death in the absence of the limb bud represents a modification of the normal mechanisms that govern neuronal death and survival, or whether it reflects the expression of mechanisms that are different from those that normally cause cell death. Hamburger and Yip (1984), studying sensory neurons in the chick embryo dorsal root ganglion (DRG), also found that cell death was accelerated in the absence of the developing wing bud. Their interpretation was that the accelerated cell death represented a modification of the normal mechanisms, where death is thought to result from the competition for trophic macromolecules supplied by the periphery. Work by Carr and Simpson (1982) in the DRG indicates that the interactions between embryonic sensory neurons and the periphery are more complicated than previously proposed, and they suggest a role for local as well as distant trophic factors in mediating neuron survival. The question of whether the accelerated death of motoneurons in the absence of the developing limb bud is the same as normal motoneuron death remains open. This question is of central importance to understanding the phenomenon of embryonic neuronal death. Future studies using limbless embryos might help resolve this issue.

\section{References}

Carr, V. M., and S. B. Simpson, Jr. (1982) Rapid appearance of labeled degenerating cells in the dorsal rool ganglia after exposure of chick embryos to tritiated thymidine. Dev. Brain Res. 2: 157-162.

Carrington, J. L., and J. F. Fallon (1983) Early ectoderm interactions of the limb bud affected by the limbless mutation. Anat. Rec. 205: $31 \mathrm{~A}$.

Carrington, J. L., and J. F. Fallon (1984) The stages of flank ectoderm capable of responding to ridge induction in the chick embryo. J. Embryol. Exp. Morphol. 84: 19-34.

Chu-Wang, I.-W., and R. W. Oppenheim (1978a) Cell death of motoneurons in the chick embryo spinal cord. I. A light and electron microscopic study of naturally occurring and induced cell loss during development. J. Comp. Neurol. 177: 33-58.

Chu-Wang, I.-W., and R. W. Oppenheim (1978b) Cell death of motoneurons in the chick embryo spinal cord. II. A quantitative and qualitative analysis of degeneration in the ventral root, including evidence for axon outgrowth and limb innervation prior to cell death. J. Comp. Neurol. 177: 59-86.

Fallon, J. F., J. M. Frederick, J. L. Carrington, M. E. Lanser, and B. K. Simandl (1983) Studies on a limbless mutant in the chick embryo. In Limb Development and Regeneration. Proceedings of the Third International Conference on Limb Morphogenesis and Regeneration, Part A, J. F. Fallon and A. I. Caplan, eds., pp. 33-43, Liss, New York.

Hamburger, V. (1934) The effects of wing bud extirpation on the development of the central nervous system in chick embryos. J. Exp. Zool. 68: 449-494.

Hamburger, V. (1958) Regression versus peripheral control of differentiation in motor hypoplasia. Am. J. Anat. 102: 365-409.
Hamburger, V. (1975) Cell death in the development of the lateral motor column of the chick embryo. J. Comp. Neurol. 160: 535-546.

Hamburger, V., and H. L. Hamilton (1951) A series of normal stages in the development of the chick embryo. J. Morphol. 88: 49-92.

Hamburger, V., and R. Levi-Montalcini (1949) Proliferation, differentiation and degeneration in the spinal ganglia of the chick embryo under normal and experimental conditions. J. Exp. Zool. 111: 457501 .

Hamburger, V., and R. W. Oppenheim (1982) Naturally occurring neuronal death in vertebrates. Neurosci. Comment. 1: 39-55.

Hamburger, V., and J. W. Yip (1984) Reduction of experimentally induced neuronal death in the spinal ganglia of the chick embryo by nerve growth factor. J. Neurosci. 4: 767-774.

Harris, W. A. (1982) The transplantation of eyes to genetically eyeless salamanders: Visual projections and somatosensory interactions. $J$. Neurosci. 2: 339-353.

Harris, W.A. (1983) The eyeless axolotl: Experimental embryogenetics and the development of the nervous system. Trends Neurosci. 6:505510.

Hollyday, M. (1981) Rules of motor innervation in chick embryos with supernumerary limbs. J. Comp. Neurol. 202: 439-465.

Hollyday, M., and V. Hamburger (1976) Reduction of the naturally occurring motor neuron loss by enlargement of the periphery. J. Comp. Neurol. 170: 311-320.

Hollyday, M., and V. Hamburger (1977) An autoradiographic study of the formation of the lateral motor column in the chick embryo. Brain Res. 132: 197-208.

Hollyday, M., and L. Mendell (1976) Analysis of moving supernumerary limbs of Xenopus laevis. Exp. Neurol. 51: 316-324.

Hollyday, M., V. Hamburger, and J. M. G. Farris (1977) Localization of motor neuron pools supplying identified muscles in normal and supernumerary legs of chick embryos. Proc. Natl. Acad. Sci. USA 74. 3582-3586.

Humphrey, R. R. (1969) A recently discovered mutant "eyeless" in the Mexican axolotl (Ambystoma mexicanum). Anat. Rec. 163: 306.

Konigsmark, B. W. (1970) Methods for the counting of neurons. In Contemporary Research Methods in Neuroanatomy, W. J. H. Nauta and S. O. E. Ebbesson, eds., pp. 315-380, Springer-Verlag, New York.

Laing, N. G. (1982a) Timing of motoneuron death in brachial and lumbar regions of the chick embryo. Dev. Brain Res. 5: 181-186.

Laing, N. G. (1982b) Motor projection patterns to the hind limb of normal and paralysed chick embryos. J. Embryol. Exp. Morphol. 72 269-286.

Lamb, A. H. (1979) Ventral horn cell counts in a Xenopus with naturally occurring supernumerary hindlimbs. J. Embryol. Exp. Morphol. 49: 13-16.

Lamb, A. H. (1981) Target dependency of developing motoneurons in Xenopus laevis. J. Comp. Neurol. 203: 157-171.

Lamb, A. H. (1984) Motoneuron death in the embryo. Crit. Rev. Clin. Neurobiol. 1: 141-179.

Lanser, M. E., and J. F. Fallon (1984) Development of the lateral motor column in the limbless mutant chick embryo. J. Neurosci. 4 . 2043-2050.

LeDouarin, N. (1980) The ontogeny of the neural crest in avian embryo chimaeras. Nature 286: 663-669.

LeDouarin, N., and G. Barq (1969) Sur l'utilisation des cellules de la Caille japonaise comme 'marqueurs biologique' en embryologie experimentale. C. R. Acad. Sci. Paris, Ser. D 269: 1543-1546.

Maheras, H. M., and E. D. Pollack (1985) Quantitative compensation by lateral motor column neurons in response to four functional hindlimbs in a frog tadpole. Dev. Brain Res. 19: 150-154.

Oppenheim, R. W. (1981) Neuronal cell death and some related regressive phenomena during neurogenesis: A selective historical review and progress report. In Studies in Developmental Neurobiology. Es says in Honor of Viktor Hamburger, W. M. Cowan, ed., pp. 74-133, Oxford U. P., New York.

Oppenheim, R. W., and C. Majors-Willard (1978) Neuronal cell death in the brachial spinal cord of the chick is unrelated to the loss of polyneuronal innervation in wing muscle. Brain Res. 154: 148-152.

Oppenheim, R. W., I.-W. Chu-Wang, and J. L. Maderdrut (1978) Cell death of motoneurons in the chick embryo spinal cord. III. The differentiation of motoneurons prior to their induced degeneration following limb bud removal. J. Comp. Neurol. 177: 87-112.

Prahlad, K. V., G. Skala, D. G. Jones, and W. E. Briles (1979) Limbless: A new genetic mutant in the chick. J. Exp. Zool. 209: 422-434. 
Prestige, M. C. (1967) The control of cell number in the lumbar ventral horns during the development of Xenopus laevis tadpoles. J. Embryol Exp. Morphol. 18: 359-387.

Shorey, M. L. (1909) The effect of the destruction of peripheral areas on the differentiation of the neuroblasts. J. Exp. Zool. 7: 25-64.

Stirling, R. V., and D. Summerbell (1977) The development of functional innervation in the chick wing-bud following truncations and deletions of the proximo-distal axis. J. Embryol. Exp. Morphol. 41. 189-207.

Sullivan, G. E. (1962) Anatomy and embryology of the wing musculature of the domestic fowl (Gallus). Aust. J. Zool. 10: 458-516.
Tosney, K. W., and L. T. Landmesser (1984) Pattern and specificity of axonal outgrowth following varying degrees of chick limb bud ablation. J. Neurosci. 4: 2518-2527.

Wenger, B. S. (1951) Determination of structural patterns in the spinal cord of the chick embryo studied by transplantations between brachial and adjacent levels. J. Exp. Zool. 116: 123-164.

Whitelaw, V., and M. Hollyday (1983) Thigh and calf discrimination in the motor innervation of the chick hindlimb following deletions of limb segments. J. Neurosci. 3: 1199-1215. 